\title{
UTILIZAÇÃO SIMULTÂNEA DAS METODOLOGIAS APQP E DFLSS NO PROCESSO DO DESENVOLVIMENTO DE PRODUTO EM UMA EMPRESA DO SETOR AUTOMOTIVO
}

\author{
SIMULTANEOUS USE OF APQP AND DFLSS METHODOLOGIES IN THE \\ PRODUCT DEVELOPMENT PROCESS IN A COMPANY IN THE AUTOMOTIVE \\ SECTOR
}

Marcos Aurelio Alves Mestrando em Engenharia Mecânica Universidade de Taubaté - UNITAU. Taboão da Serra, São Paulo - Brasil. socram2011@hotmail.com

Miroslava Hamzagic Doutora em Engenharia de Produção Universidade de Taubaté - UNITAU.

Taubaté, São Paulo - Brasil. miroslava.hamzagic@unitau.br Mestre em Engenharia Mecânica Universidade de Taubaté - UNITAU.

Taubaté, São Paulo - Brasil. ivair.santos@unitau.br

\begin{abstract}
Resumo
A presente pesquisa apresenta uma análise das diversas abordagens de metodologia de desenvolvimento de produtos, delineando suas dimensões básicas em relação à integração com as empresas. Propõe-se a utilização simultânea de duas metodologias consagradas, o Advanced Product Quality Planning (APQP) e o Design For Lean Six Sigma (DFLSS), para o gerenciamento de desenvolvimento de produtos, proporcionando para uma empresa automotiva menos retrabalhos e diminuição na produção de refugos de matéria-prima. O objetivo desta pesquisa foi traçar uma metodologia para suprir as necessidades dos engenheiros da área de desenvolvimento de produtos de gerenciar as atividades envolvidas no processo de desenvolvimento de produtos. $\mathrm{O}$ artigo consiste em um estudo de caso qualitativo, com suas conclusões apoiadas em dados, iniciando com uma ampla pesquisa bibliográfica das metodologias e a apresentação de um estudo de caso em uma empresa automotiva de cintos de segurança. Com o conhecimento adquirido por meio do estado da arte e o resultado obtido mediante o estudo de caso, concluiu-se que a união de duas metodologias contribuiu para tornar o gerenciamento de produtos mais acessível, permitindo para toda a equipe envolvida tomadas de decisões mais assertivas e desenvolvimento de produtos de maior qualidade.
\end{abstract}

Palavras-chave: Processo de Desenvolvimento de Produtos (PDP). Six Sigma. Design for Lean Six Sigma. Metodologia de desenvolvimento.

\section{Abstract}

This research presents an analysis of the different approaches to product development methodology, outlining its basic dimensions in relation to integrations with companies. This article present a proposal for the simultaneous use of two established methodologies, the advanced product quality planning (APQP) and the Design for Lean Six Sigma (DFLSS), for managing the development of new products. Providing for a company that use it, less rework in production development and reduction in the production of waste raw materials. The main objective of this article is to develop a methodology that make up the needs that engineers in the product development area have to manage and develop the activities involved in the Product Development Process (PDP). The article refers to a qualitative case study, with its conclusions supported by data, providing a broad bibliographic survey of methodologies and the presentation of a case study in an automotive seat belt company. With the knowledge acquired in the formation of the state of the art and without the results found in the case study, it concludes that the union of two methodologies makes product management more accessible, providing more decision-making for the entire team working on this development with assertiveness and development of products with more quality.

Keywords: Product development process (PDP). Six Sigma. Design for Lean Six Sigma. Development methodology.

Cite como

American Psychological Association (APA)

Alves, M. A., Hamzagic, M., \& Santos, I. A. (2021, set./dez.). Utilização simultânea das metodologias APQP e DFLSS no processo do desenvolvimento de produto em uma empresa do setor automotivo. Revista de Gestão e Projetos (GeP), $12(3), 60-87$. https://doi.org/10.5585/gep.v12i3.20788 


\section{Introdução}

Por causa do atual cenário econômico globalizado, identifica-se uma crescente concorrência entre as empresas, que estão vivenciando notáveis momentos com a inovação da tecnologia e com a variedade de novos projetos, buscando desenvolver produtos com algum diferencial e com valores acessíveis aos consumidores (Rozenfeld et al., 2012). Elas necessitam aperfeiçoar seus processos produtivos, da mesma forma que $\mathrm{o}$ ferramental empregado no controle da produção, mirando sempre redução de dispêndios (Palisaitiene, Sundin \& Poksinska, 2018). Portanto, um diferencial que esteja ligado totalmente com a qualidade do produto desenvolvido. Diante deste cenário as empresas devem estar capacitadas a produzir com qualidade. Qualidade é um termo empregado em vários princípios, destacando entre eles conformidade com o custo, características dos produtos, qualidade referente a produção e entrega com o atendimento dos requisitos definidos pelo cliente, certificando a garantia para o cliente final (Lobo, 2020).

Porquanto, no momento em que as empresas estão passando, o processo de desenvolvimento de produtos (PDP) é um diferencial para assegurar a qualidade. Por este motivo, ocorre a necessidade de ferramentas apropriadas para a realização de projetos muito variados (Oliveira, França \& Rangel, 2018). As empresas para aprimorarem seu nível competitivo utilizam uma série de soluções para promoverem redução de dispêndios e prazos de lançamento de seus produtos. Portanto, um PDP estruturado e enxuto traz uma resposta diferenciada para as empresas (Reis, Costa \& Milan, 2017). Muitos métodos e ferramentas da qualidade são praticados nos dias atuais para proporcionarem melhorias nos processos de produção e assertividade na tomada de decisões (Schineider \& Gasparotto, 2020). Duas metodologias muito significativas empregadas pelo setor automotivo são o APQP (Advanced Planning for Product Quality), com a função de estabelecer procedimentos e prazos nas etapas da manufatura do produto, definindo uma gestão estruturada para o PDP, uma vez que ao final do desenvolvimento é primordial que o produto encontre-se aprovado e que os requisitos estejam sendo cumpridos para preservar a qualidade do produto final, auxiliando a produção de outros itens (Rocha \& Salerno, 2014) e o DFLSS (Design for Lean Six Sigma), proveniente da integração das metodologias Six Sigma e Lean Manufacturing, sendo que o Six 
Sigma dispõe de um método para solução de problemas com ferramentas estatísticas e o Lean Manufacturing visa melhorar a velocidade do processo e redução do lead time (Werkema, 2020).

Com base nestas duas metodologias, a melhoria contínua aplicada às técnicas do PDP se faz necessária, porque o mercado está cada vez mais exigente, tanto na qualidade final do produto quanto no valor agregado. Desta forma, a presente pesquisa apresenta um estudo sobre a utilização destas duas técnicas unificadas para o PDP. Considerando este contexto, esta pesquisa decidiu pela pergunta norteadora: De que maneira duas metodologias consagradas, APQP e DFLSS, podem auxiliar num melhor planejamento do desenvolvimento de produto?

O objetivo desta pesquisa foi traçar uma metodologia para suprir as necessidades dos engenheiros da área de desenvolvimento de produtos de gerenciar as atividades envolvidas no processo de desenvolvimento de produtos. Para tanto, estruturando seu conteúdo e suas variáveis, uma vez que essas técnicas variam de acordo com as políticas de produtos, buscando sempre alcançar as expectativas do cliente relacionadas ao produto de qualidade.
A contribuição desta pesquisa está em promover uma metodologia com várias atividades para nortear o gerenciamento do PDP, demonstrando por meio de um estudo de caso qualitativo, a assertividade de um desenvolvimento após um amplo estudo do periférico a que este produto pertence. A revisão da literatura no que se refere aos principais conceitos será dissertada na próxima seção. A metodologia empregada, assim como as análises e discussões obtidos com o estudo de caso serão apresentados na terceira e quarta seção respectivamente. Por fim, a última seção trata das conclusões e considerações finais.

\section{Fundamentação teórica}

\subsection{Processo de desenvolvimento de produtos $-P D P$}

O PDP sempre esteve presente para satisfazer as necessidades das empresas. Muitas delas, para sobreviverem ao mercado cada vez mais competitivo, utilizam várias metodologias de gestão para seus ativos, sendo uma delas a subcontratação de serviços, também descrita como terceirização ou outsourcing (Marion, Eddleston, Friar \& Deeds, 2015). Com o surgimento da revolução industrial, ocorreu modificações nos conceitos, processos de produção e gerenciamento de produtos, pretendendo maior rapidez com 
baixos impactos negativos (Alves \& Azevedo, 2016).

As empresas automotivas aplicam processos disciplinados para o desenvolvimento de produtos, necessitando se adaptar e atender às exigências normativas. Segundo Rozenfeld et al. (2012), o PDP desenvolve-se com a utilização de um conjunto de atividades que o direcionam para a eficácia do projeto de um produto e/ou de um processo produtivo, seguindo as necessidades do mercado, suas exigências legais, as tecnologias, as partes financeiras e o tempo.

A gestão do PDP torna-se complicada por causa da dinâmica envolvida no desenvolvimento de um produto. A natureza dessa dinâmica são as atividades envolvidas nesse processo, as quais interagem com as atividades das empresas, necessitando respeitar os fatores ambientais, políticos, econômicos, tecnológicos e sociais (Alves \& Azevedo, 2016). Essa dinâmica tem como consequência o ciclo frequente do tipo (projetar/construir/testar), ocorrido nas atividades empregadas no desenvolvimento de produtos, contendo sucessivos ajustes e alterações, bem como interações entre etapas da cadeia de produção (Clark \& Fujimoto, 1991).

O PDP de acordo com Rozenfeld et al. (2012), ilustrado na Figura 1, é formado por três macro fases: Pré-Desenvolvimento, Desenvolvimento e Pós-Desenvolvimento.

\section{Figura 1.}

Fases do Processo de Desenvolvimento de Produto

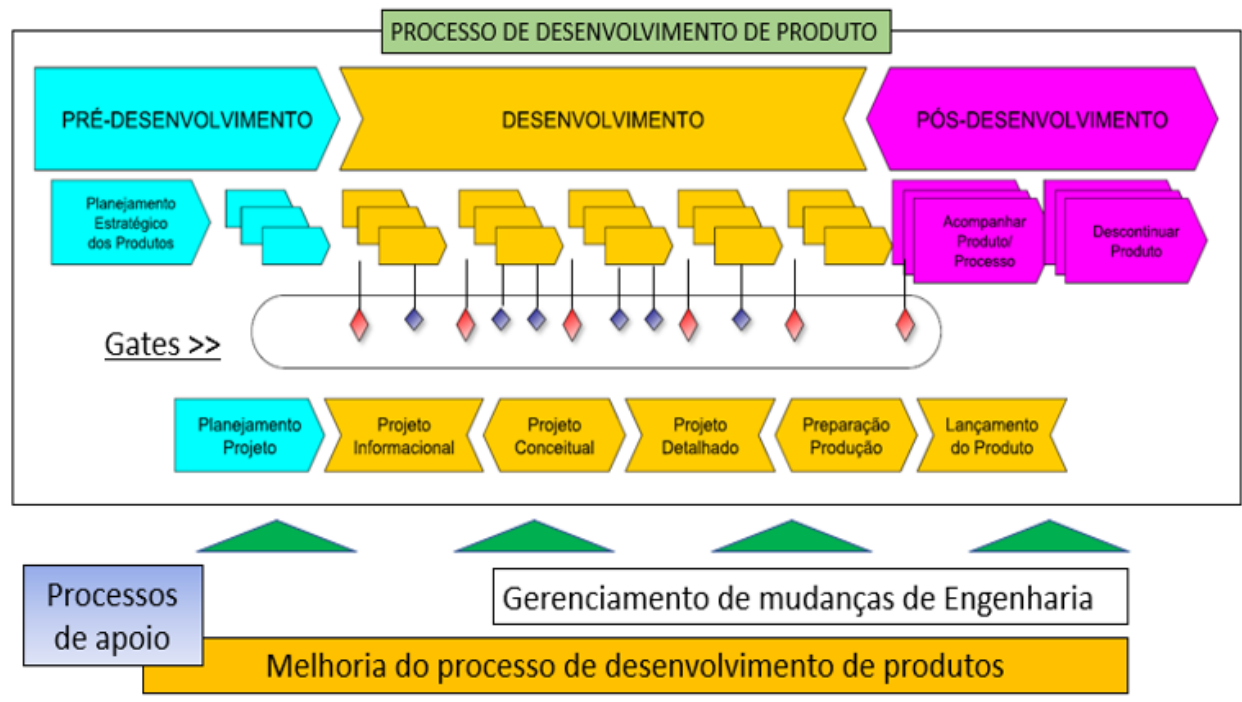

Fonte: adaptado de Rozenfeld et al. (2012). 
O Pré-Desenvolvimento engloba o planejamento estratégico dos produtos, definindo os objetivos, as metas e os requisitos dos clientes, que deverão ser descritos no escopo do projeto. $\mathrm{O}$ Desenvolvimento inicia-se no projeto informacional, com a responsabilidade de criar, partindo do escopo do projeto, seguido do projeto conceitual, com as missões de gerar soluções para o projeto e definir a melhor diretriz para o desenvolvimento, prosseguindo no projeto detalhado, cujos propósitos são planear a concepção do produto e transformá-la em especificações finais, seguido pela preparação da produção, garantindo a

\subsection{As indústrias automotivas}

Na década de 1970 o PDP foi um marco para as indústrias automotivas brasileiras, tendo como objetivos a inovação de produtos, o controle dos processos, a redução de custos e a garantia do mercado consumidor (Toledo et al., 2002). Sendo que a busca por melhores resultados fez com que as empresas automotivas atendessem à normatização dos sistemas de gestão da qualidade (Martins, 2018).

Após a reformulação acontecida nos anos de 1990, as indústrias automotivas passaram a ser constituídas de empresas certificação do produto por meio dos resultados alcançados na corrida piloto. Finaliza-se o processo com o lançamento do produto.

O Pós-Desenvolvimento é designado para o acompanhamento do produto e processo. Tem a função de analisar o processo desde o seu início, para que sejam evidenciados os erros cometidos neste projeto, para que sejam evitados nos próximos desenvolvimentos. Sua execução auxilia a empresa a aprender com os erros que foram cometidos durante a execução e garantem uma elevação de conhecimentos descritos nos documentos (Rozenfeld et al., 2012).

transnacionais. Muitas delas costumam desenvolver produtos em suas unidades, para atenderem às necessidades das montadoras locais ou para exportarem. Algumas dessas unidades possuem competências técnicas para desenvolver essas atividades e competências para gerenciar tais desenvolvimentos (Toledo et al., 2002).

Com a finalidade de controlar a invasão do mercado concorrente, o PDP possibilitou o crescimento e a modernização desse setor. As empresas automotivas, para acompanhar as montadoras, adquiriram máquinas 
modernas e aprimoraram seus métodos e processos, com o propósito de assegurar a qualidade dos seus produtos (Toledo et al., 2002).

O setor automotivo atualmente é um dos segmentos mais competitivos do Brasil e do mundo. O considerável número de marcas e estilos oferecidos por este segmento, determinam um dos mercados mais dinâmicos da economia, sendo composto por uma forte cadeia econômica e social. Para alcançar sucesso neste segmento é necessário oferecer o melhor produto, com uma excelente qualidade e com menor valor (Martins, 2018).

Nesse contexto, algumas indústrias adotaram modificar significativamente $\mathrm{o}$ gerenciamento do PDP, focando em: divisão das tarefas entre as unidades matrizes e locais; integração e coordenação das equipes; atendimento aos processos cada vez mais exigentes em relação a prazo, qualidade e custo dos novos produtos; descentralização e centralização das atividades e envolvimento de clientes e fornecedores com os projetos (Toledo et al., 2002).

Normalmente as indústrias automotivas obedecem as sistemáticas descritas no manual do APQP, sendo sua utilização uma exigência da IATF 16949:2016, que é um certificado de qualidade obrigatório para o setor automotivo (Martins, 2018). Com a certificação concedida, a indústria qualifica-se, podendo negociar novos projetos e expandir seus negócios. O APQP oferece diretrizes para planejar o desenvolvimento do produto, garantindo a qualidade e evitando desperdícios, apresentando benefícios ao desenvolvimento de produtos ou serviços, tendo como propósito a padronização das sistemáticas da qualidade, para que os fornecedores atendam aos requisitos das montadoras, sem esforços desnecessários nem acréscimo no valor do produto (APQP, 2008).

O cenário mundial determina um desafio para as indústrias automotivas triunfarem diante da competitividade, onde atender a velocidade em que ocorrem as mudanças e as inovações são cada vez mais constantes. $\mathrm{O}$ atendimento destes prazos se tornaram um diferencial para a sobrevivência das empresas, onde utilizar metodologia de gestão é considerado uma prática que incorpora grande diferencial competitivo (Santos \& Oliveira, 2019). 


\subsection{Ferramenta APQP no desenvolvimento de produto}

O APQP foi desenvolvido pela General Motors, Ford e Chrysler. É designado como um método das empresas automotivas que têm o objetivo de suprir as necessidades de desenvolver e aperfeiçoar um produto mais confiável (Schineider \& Gasparotto, 2020). O manual do APQP descreve o procedimento do instrumento, com recomendações e diretrizes para o fornecedor realizar o plano de desenvolvimento de produtos, modelos de formulários, ferramentas de verificações (checklist) e outros mecanismos a fim de acompanhar o desenvolvimento do projeto (APQP, 2008).
As cinco fases do APQP são bem estruturadas para $\mathrm{o}$ processo $\mathrm{de}$ desenvolvimento de produto, e seu objetivo específico é garantir o atendimento das necessidades e das expectativas do cliente. De acordo com Pissinatti, Franco e Rezende (2014), o APQP é a principal ferramenta a ser utilizada para se adquirir a certificação QS-9000. Ela é responsável por gerenciar todo o desenvolvimento do produto, iniciando-se no fornecedor, com o fechamento do contrato, até a validação das peças em produção, conforme ilustrado na Figura 2.

\section{Figura 2.}

Fases do Processo de Desenvolvimento do Produto Segundo O Advanced Product Quality Planning $(A P Q P)$

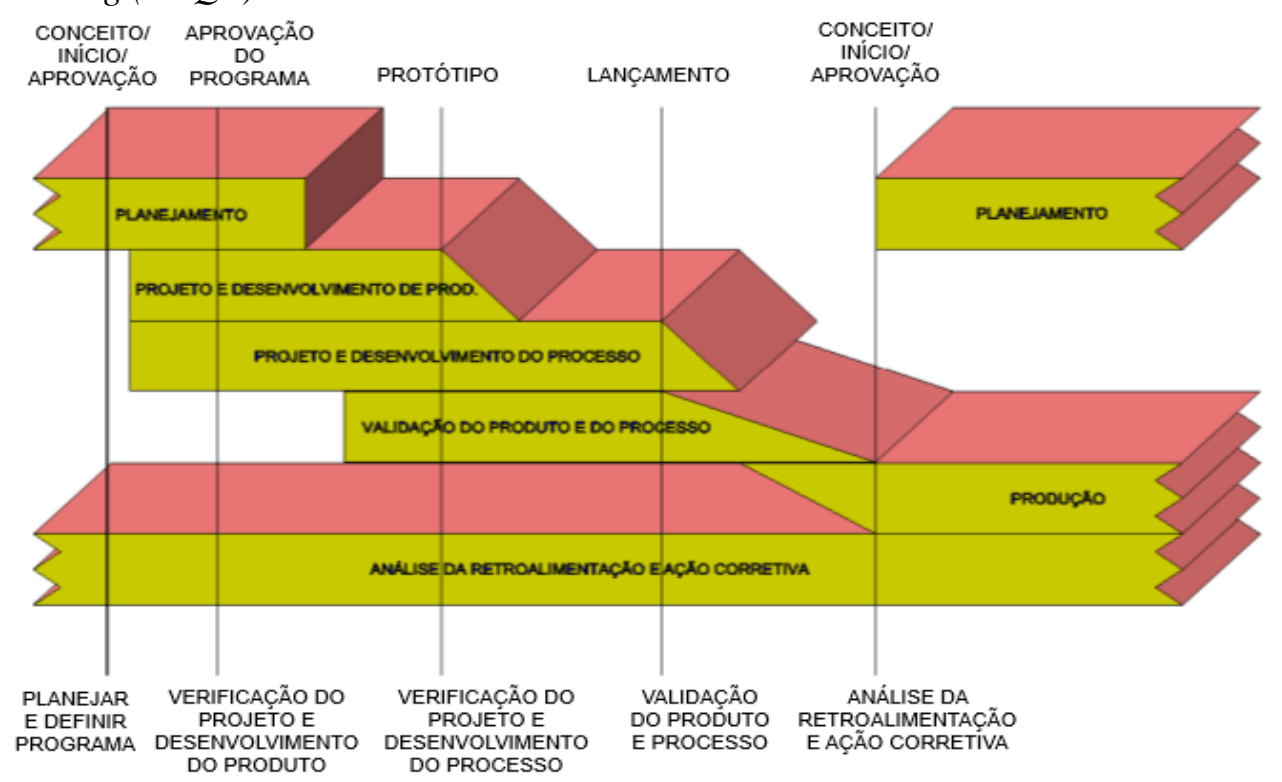

Fonte: Adaptado de APQP (2008). 
A primeira fase do APQP é o Planejamento, define-se os requisitos dos clientes e as expectativas que eles têm sobre o programa (APQP, 2008). A compreensão total das necessidades dos clientes é o objetivo desta fase, não devendo prosseguir no desenvolvimento do produto sem o total entendimento. A elaboração das versões preliminares da lista de materiais, de metas de confiabilidade e fluxograma do processo, finalizam esta fase (Albertin, 2018).

A segunda fase é o Projeto e Desenvolvimento do Produto, onde é definido melhor as características do projeto, analisando-o com as especificações de engenharia e material, e executando a manufatura do protótipo (APQP, 2008). Nesta fase as características especiais e recursos de Design deverão estar praticamente em formato final. É realizado uma análise do efeito e modos de falha do produto, o DFMEA. São realizados os desenhos, as especificações de engenharia, planos de amostragem, técnica de medição e produzida a lista de materiais (Albertin, 2018).

O Projeto e Desenvolvimento do Processo é a terceira fase do APQP, o foco agora é desenvolver um processo que garantirá os requisitos, necessidades e expectativas do cliente para 0 desenvolvimento do produto, estabelecidos anteriormente. São realizadas várias atividades, dentre elas o plano do sistema de medição, revisão do diagrama de fluxo do produto, definição de padrões, especificações de embalagem, FMEA do processo, plano de controle, instruções do processo, estudos de capacidade do processo, dispositivos a prova de falhas, análise crítica da gerência, sistemas de controle de linha e outros (Albertin, 2018).

A penúltima fase é a Validação do Produto e Processo, nesta fase é validado o processo e seus mecanismos de controle, definidos anteriormente. Avaliando a execução da produção, descrevendo seus requisitos e condições obrigatórios. A validação é decorrente de um lote piloto, sendo que as peças são dimensionadas, a capacidade de produção avaliada e o sistema de medição verificados (Albertin, 2018).

A última fase descrita como Análise da Retroalimentação e Ação Corretiva, tem como objetivo reduzir a variabilidade do processo, checando se todas as características do produto atendem ao cliente, garantindo a melhoria contínua e resolução de problemas. E finalmente, o processo seguirá a produção em grande escala e o início do fornecimento do produto para os clientes (Rozenfeld et al., 2012). 
O APQP é uma metodologia estruturada, que colabora e determina fases para o desenvolvimento do produto, que favorecerão às empresas atingirem suas metas de qualidade, prazos e custos. Essa

\subsection{Metodologia design for lean six sigma}

A metodologia Design For Lean Six Sigma (DFLSS) é a união da lean manufacturing e da six sigma. Ela proporciona às organizações usufruírem os pontos fortes das duas metodologias, trabalhando na eliminação de desperdícios e variáveis de processos, com o intuito de conquistar a satisfação dos clientes. Essa metodologia deve ser utilizada quando a organização pretende desenvolver um processo ou produto; quando o método DMAIC não atende às necessidades do cliente e existe a necessidade de redesenhar ou reprojetar o processo ou o produto; e quando o processo atingiu seu nível máximo de performance (process ferramenta é utilizada em toda base de relacionamento entre fornecedor e cliente, determinando as entradas e saídas necessárias para o sucesso de um PDP (Schineider \& Gasparotto, 2020).

entitlement), havendo a necessidade de desenvolver outro (Werkema, 2012).

O six sigma não objetiva melhorar a velocidade do processo nem reduzir o lead time, e o lean manufacturing não utiliza um método para eliminar problemas com ferramentas estatísticas. Portanto, a integração entre essas duas metodologias ocorre naturalmente (Werkema, 2020).

A metodologia DFLSS utiliza um método constituído de cinco etapas, o DMADV (Define, Measure, Analyze, Design, Verify). De acordo com Werkema (2012), os quatro princípios básicos dessa metodologia segundo tradução livre de Gerald Hahn, Necip Doganaksoy e Roger Hoerl são ilustrados na Figura 3. 


\section{Figura 3.}

Princípios Básicos da Metodologia Design For Lean Six Sigma (DFLSS)

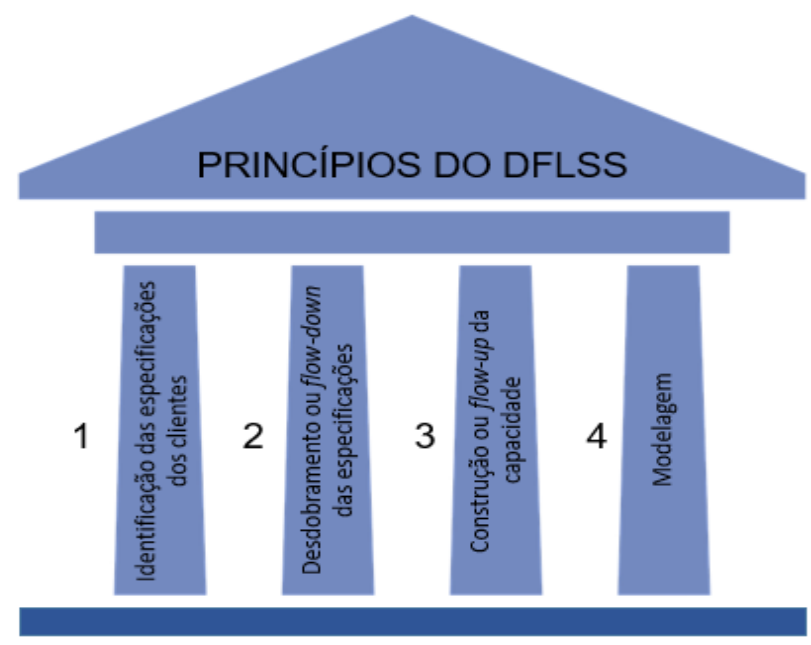

Fonte: Adaptado de Werkema (2012)

O sucesso da metodologia DFLSS inicia-se com a definição de uma equipe para executar os projetos, existindo a necessidade de uma estrutura de trabalho bem definida, com foco na melhoria contínua dos processos. O desenvolvimento dessa hierarquia na empresa deve ter o apoio dos níveis diretivos e gerenciais (Rotondaro et al., 2002).

A hierarquia desses profissionais está dividida entre patrocinadores e especialistas. Os patrocinadores são: os sponsors, responsáveis por definir e promover as diretrizes da implementação da metodologia six sigma; os sponsors facilitadores, responsáveis em assessorar os sponsors; e os champions, um representante da alta direção que deve difundir a metodologia na organização. Os especialistas são: os black belts, líderes dos projetos, com foco na melhoria contínua dos processos; os green belts, membros das equipes multifuncionais, colaboradores especialistas em suas atividades; os yellow belts, cuja função principal é executar projetos focados no desenvolvimento; e os white belts, membros da organização com conhecimento básico da metodologia six sigma, mas que contribuem para o sucesso dos projetos (Werkema, 2012). A Figura 4 ilustra o fluxograma dessa estrutura. 


\section{Figura 4.}

Hierarquia da Equipe Lean Six Sigma

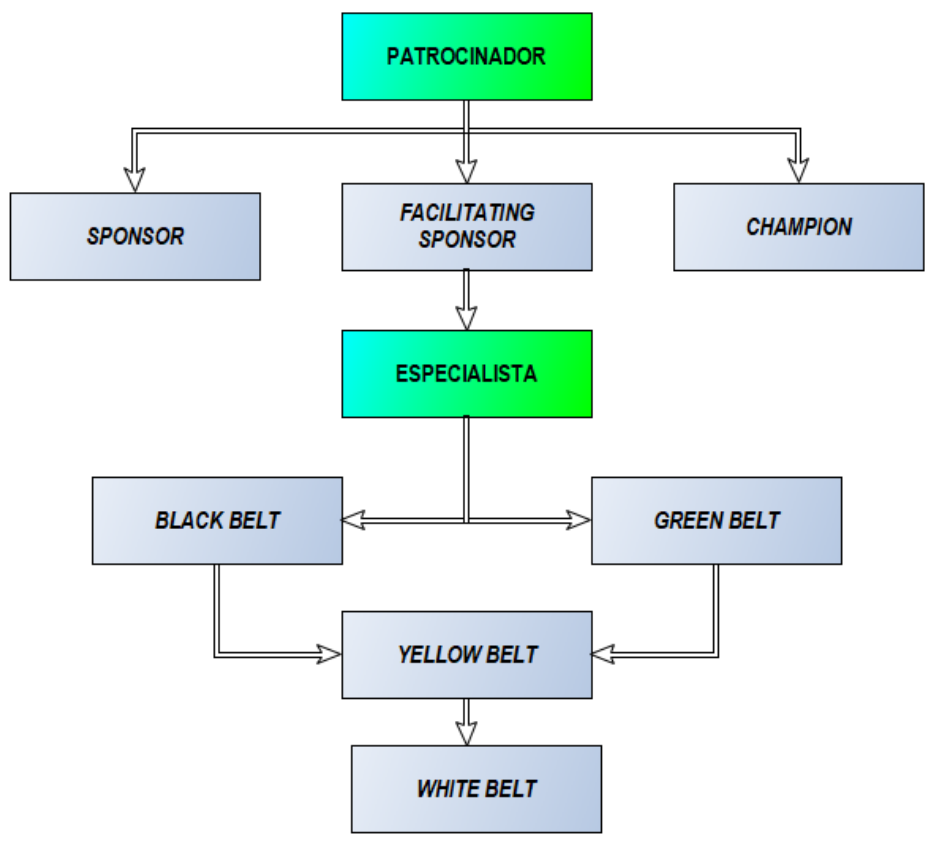

Fonte: Adaptado de Werkema (2012).

\section{Procedimentos metodológicos}

Esta pesquisa dispôs-se de uma metodologia com objetivo exploratório, baseada na abordagem qualitativa, desenvolvida por meio de estudo de caso (Alonso, Lima \& Almeida, 2016). Todo trabalho acadêmico se inicia com uma pesquisa exploratória, para entender a situação e o que há de teoria sobre o assunto (Prodanov \& Freitas, 2013). No procedimento de estudo de caso qualitativo os pesquisadores buscam alcançar seus conhecimentos partindo das percepções dos autores locais, posicionando "em suspenso" seus pontos de vista sobre a questão que está sendo estudada (Godoy, 2006).

A pesquisa qualitativa com objetivo exploratório, segundo Gerhardt e Silveira (2009) retratam como "qualitativa" a pesquisa desempenhada para investigação do entendimento do assunto pesquisado, considerando os dados analisados "não métricos". Nesta pesquisa, considerou-se os aspectos da realidade não quantificados. Godoy (2006) interpreta que uma pesquisa qualitativa para ter validade interna, suas conclusões devem ter sustentação em dados. Essa validade interna é determinada por meio da importância que a descrição 
apresentada pelo pesquisador, está representando os dados coletados.

Para a elaboração do trabalho, a técnica empregada para coletar as informações foi a pesquisa bibliográfica, baseada em artigos científicos sobre a gestão do desenvolvimento do produto, praticada por meio da metodologia APQP e DFLSS. A pesquisa bibliográfica é conceituada como a pesquisa da literatura que foi publicada de acordo com livros, revistas, publicações, páginas da internet, publicações avulsas, etc., com a finalidade de posicionar diretamente o pesquisador com determinado assunto (Silva \& Moura, 2018).

O estudo de caso foi conduzido em uma empresa automotiva de cinto de segurança, nela foi proposto a implementação da união de duas metodologias consagradas (APQP e DFLSS), no desenvolvimento de um componente do cinto de segurança. De acordo com Rozenfeld et al. (2012), os projetos realizados nas empresas estudadas são considerados como projetos incrementais, sendo projetos com pequenas alterações ou projetos derivados de projetos existentes. Godoy (1995) elucida que embora os estudos de caso sejam considerados qualitativos, podem conter dados quantitativos para alcançar alguma questão investigada. De acordo com Marconi e Lakatos (2017), o estudo de caso não detém um esquema estrutural. Nele se reúne um grande número de informações detalhadas, servindo-se de variadas técnicas de pesquisa, tendo como objetivos aprender com as situações e descrever suas complexidades

Para a execução do estudo de caso, determinou um componente do cinto de segurança para utilizar a metodologia proposta na segunda fase do APQP. A empresa citada, frequentemente desenvolve seus produtos utilizando as atividades do APQP, mas observa-se a necessidade de realizar mais atividades na segunda fase do APQP (Projeto e Desenvolvimento do Produto), por não alcançar êxito na validação da primeira proposta de protótipo desenvolvida. Neste trabalho foi utilizado as atividades do método DMADV na segunda fase do APQP com o objetivo de proporcionar decisões mais assertivas no desenvolvimento de uma proposta de protótipo. 


\section{Análises e discussões dos resultados}

\subsection{Descrição da empresa}

O estudo de caso foi realizado em uma empresa automotiva de cinto de segurança atuante no segmento desde os anos de 1950. O nome da empresa será preservado nesta pesquisa e se adotará aqui o nome Save Lives. O cinto de segurança é um item que faz parte da segurança passiva do veículo, necessitando atender às normas governamentais e exigências legais vigentes no país.

O gerenciamento do PDP é fundamental para $\mathrm{o}$ atendimento dos requisitos e a sobrevivência da empresa. Os processos e as tecnologias são gerenciados e descritos de acordo com a norma IATF 16949:2016, responsável por avaliar o

\subsection{Proposta do novo fluxo}

O PDP na empresa Save Lives é gerenciado pelo project manager do programa, que está sendo desenvolvido e por uma equipe multidisciplinar, com colaboradores de todas as áreas envolvidas. Ele gerencia as atividades descritas nas cinco fases da ferramenta APQP e realiza o acompanhamento das atividades por meio de um cronograma.

As atividades realizadas na segunda fase do APQP nessa empresa são atendimento dos processos e requisitos das montadoras, por orientar os fornecedores a satisfazerem aos clientes, por melhorias contínuas, etc.

O gerenciamento do PDP é realizado pelo setor de engenharia de desenvolvimento de produtos da empresa Save Lives, utilizando a ferramenta APQP. $\mathrm{O}$ atendimento das fases do APQP se faz necessário para garantir um produto de qualidade. Portanto, a eficiência e a eficácia desta ferramenta não serão questionadas nesta pesquisa. Será descrita uma proposta de união das atividades descritas no método DMADV na segunda fase da ferramenta APQP. As demais fases do APQP serão mantidas e devem ser executadas simultaneamente.

coordenadas pela engenharia de desenvolvimento de produto, com o apoio de outras áreas. Inicialmente o gerente da engenharia define uma equipe para realizar as atividades e o project manager acompanha o desenvolvimento e gerencia o atendimento das datas-chave e a viabilidade econômica do programa.

Na segunda fase do APQP (Projeto e Desenvolvimento do Produto), acontece o gerenciamento do desenvolvimento de produto. A proposta desta pesquisa é incrementar essa fase com as atividades 
descritas no método DMADV, da metodologia DFLSS. Entretanto, as outras fases serão seguidas conforme o manual APQP e não sofrerão alterações.

Com o cenário descrito da empresa Save Lives, viu-se a necessidade de atividades de apoio, para tomadas de decisões mais assertivas na definição de uma solução. Assim, com a utilização das atividades descritas no método DMADV, a engenharia de produto obteve uma visão mais global do problema e das interações dos outros componentes com a solução desenvolvida.

Por meio da pesquisa bibliográfica, obteve-se embasamento para propor melhorias na segunda fase do APQP, incrementando atividades nessa fase para direcionar o project manager e a equipe multidisciplinar tomar decisões mais assertivas.

\subsection{Implementação do fluxo proposto}

O conjunto do cinto de segurança é composto de vários componentes. A empresa Save Lives possui um grande setor tecnológico, em que são desenvolvidas várias soluções, sempre trabalhando no desenvolvimento de produtos e/ou na melhoria contínua dos produtos já existentes.

O fluxo proposto foi utilizado no desenvolvimento de um terminal de ancoragem do retrator. Esse componente é responsável por fixar o cadarço do cinto de segurança à estrutura do veículo. A Figura 5 ilustra o conjunto do cinto de segurança, evidenciando o terminal de ancoragem. 
Figura 5.

Conjunto do Cinto de Segurança: Terminal de Ancoragem

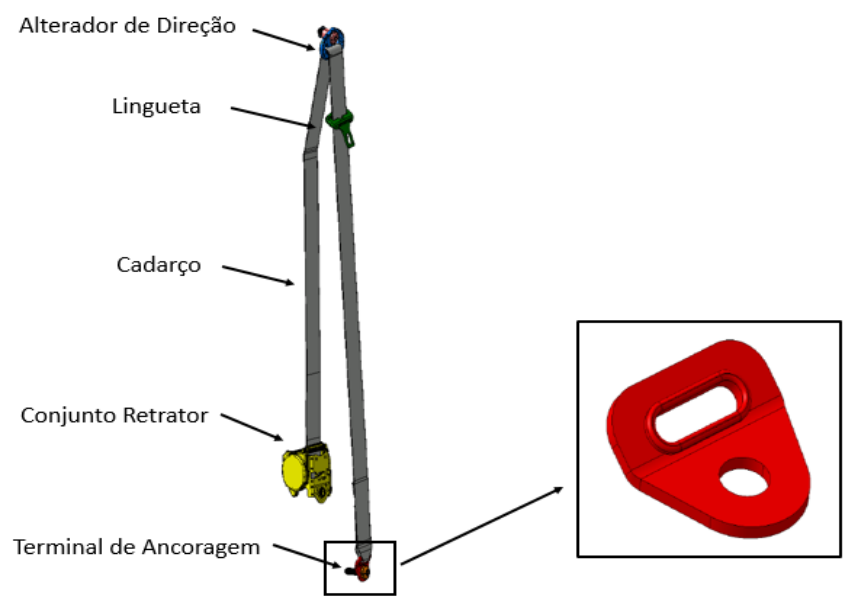

Fonte: Elaborado pelos autores, 2021.

No fluxo proposto neste trabalho, as atividades do método DMADV da metodologia DFLSS foram aplicadas nesse desenvolvimento, porém, utilizou-se apenas algumas das atividades desse método, descritas a seguir. A utilização das atividades estão ligadas ao projeto que está sendo desenvolvido. Neste caso, a equipe definiu que não havia necessidade de algumas atividades descritas no método.

\subsubsection{Execução da etapa define}

A primeira atividade da etapa define, realizada no desenvolvimento do terminal de ancoragem, foi o project charter. $\mathrm{Na}$ primeira reunião com a equipe de desenvolvimento de produto, foi preenchido o documento, com o qual foi possível registrar as premissas do programa e deixar toda a equipe alinhada com os requisitos e objetivos. A Figura 6 ilustra esse documento. 


\section{Figura 6.}

\section{Project Charter}

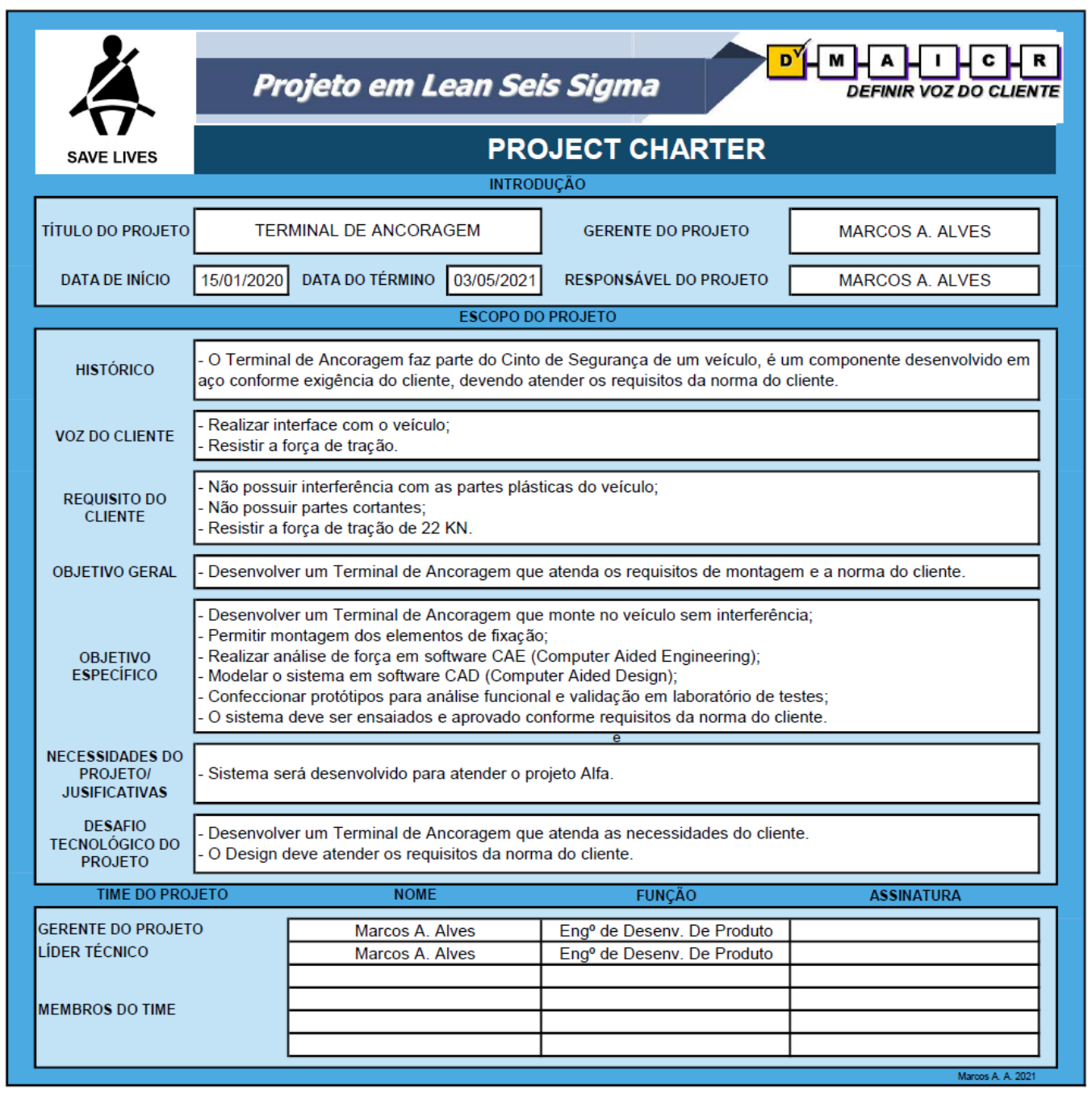

Fonte: Elaborado pelos autores (2021).

Com a conclusão do project charter, toda a equipe ficou alinhada com $\mathrm{o}$ programa. Para maior clareza das atividades e dos prazos foi realizado outro documento, um cronograma preliminar, descrevendo todas as etapas do DMADV e suas atividades. A Figura 7 ilustra o cronograma e as atividades realizadas nesse desenvolvimento. 


\section{Figura 7.}

\section{Cronograma}

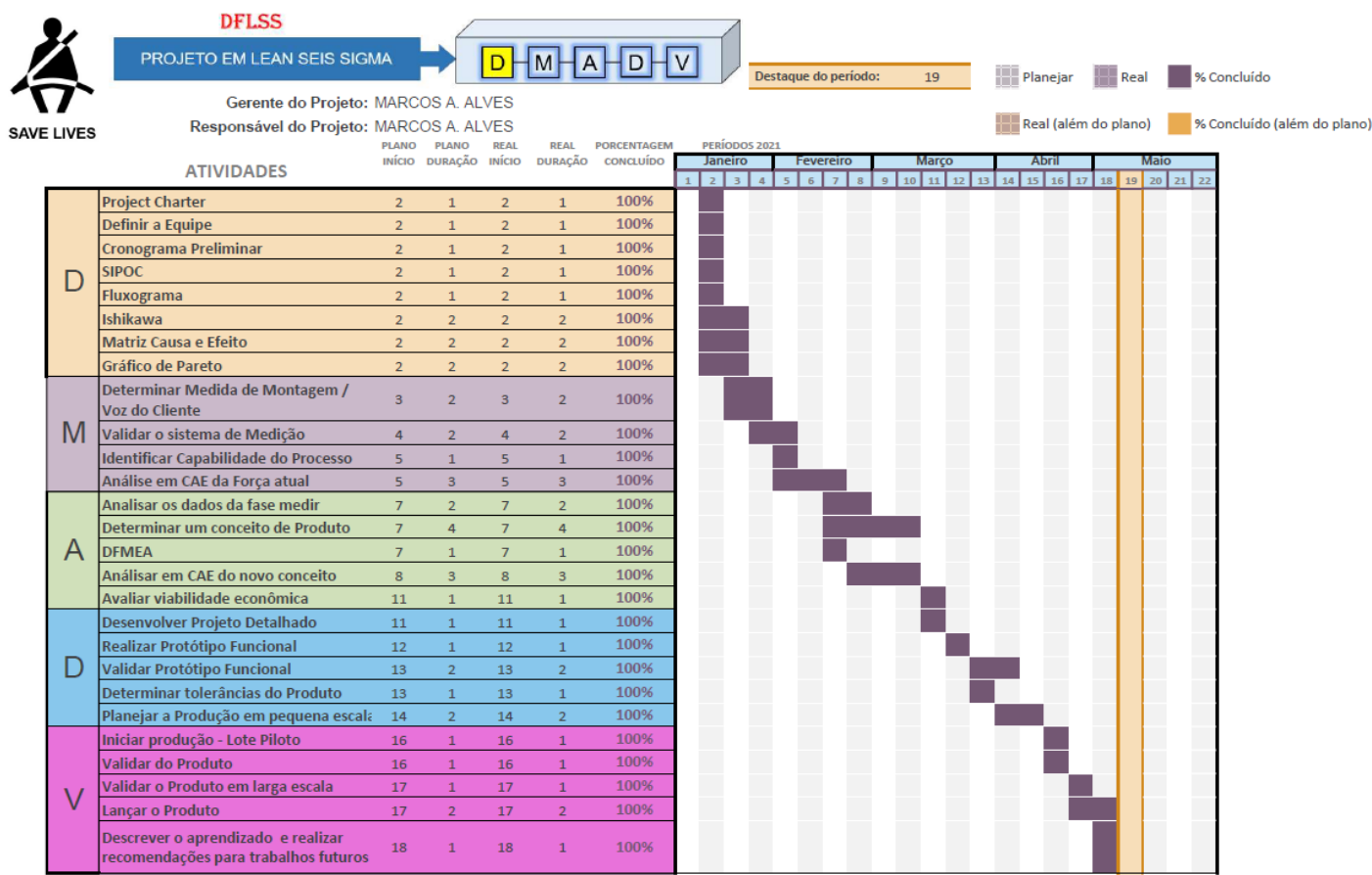

Fonte: Elaborado pelos autores (2021).

Com essas duas atividades, toda a equipe ficou alinhada com as tarefas e os prazos. Agora, o foco passou a ser a realização de uma solução robusta, o entendimento dos processos envolvidos na manufatura e a visualização das interfaces que esse componente terá com o veículo e com os outros componentes. Portanto, foram realizadas várias atividades para adquirir know-how desse produto, iniciando-se por uma análise SIPOC (Suppliers, Inputs, Process, Outputs, Customers), cujo objetivo principal é proporcionar uma visão dos processos para toda a equipe. A Figura 8 ilustra a análise SIPOC. 
Figura 8.

Análise SIPOC

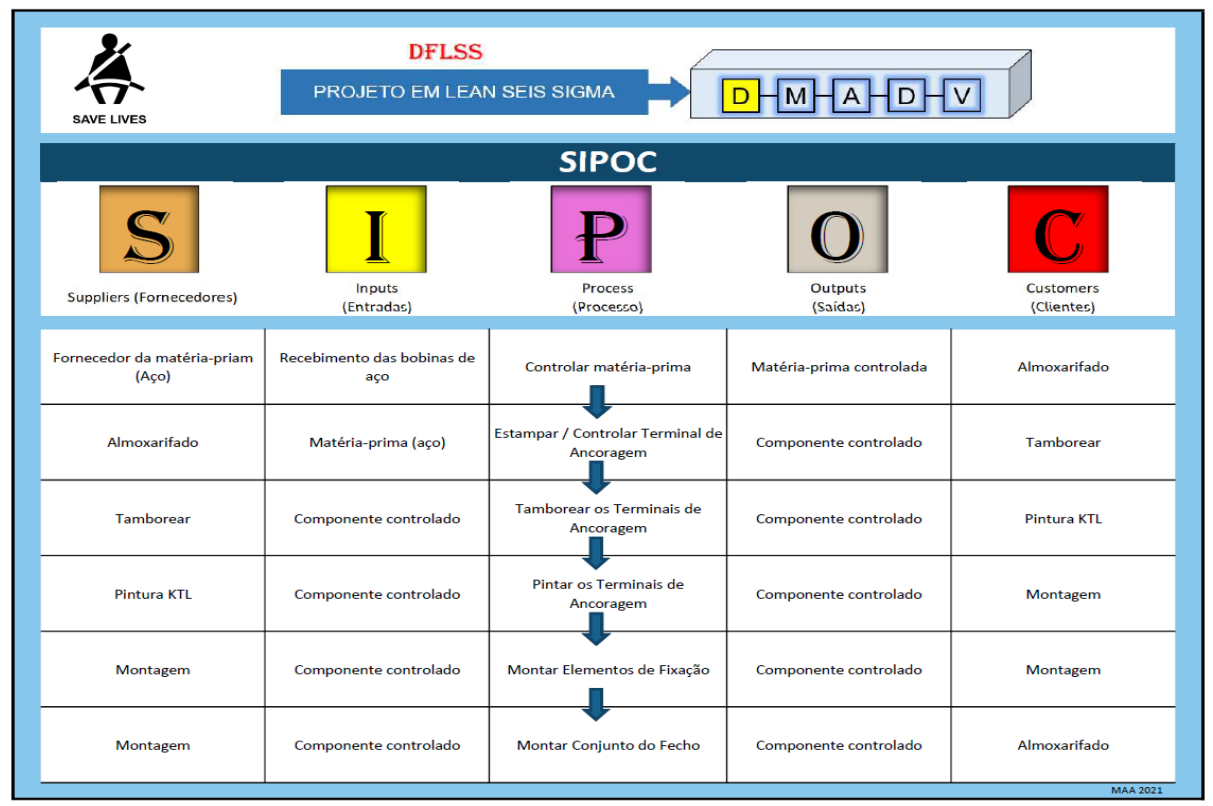

Fonte: Elaborado pelos autores, 2021.

Outra maneira de visualizar os processos envolvidos na manufatura é a realização de um fluxograma. O fluxograma é uma representação gráfica, com símbolos estandardizados, de todas as etapas de um processo, apresentando uma sequência do início ao fim, com o objetivo de proporcionar uma visão do projeto atual e ideias para novos projetos (Rossetto, Toso \& Rodrigues, 2019).

Com o entendimento de toda a equipe em relação aos processos envolvidos, a próxima atividade a ser realizada na etapa define foi a utilização da técnica 5W2H, que consiste em cinco perguntas, que, quando bem respondidas, possibilitam identificar rotinas e dados significativos no processo produtivo e reconhecer quem é quem dentro da empresa.

A equipe, após empregar a técnica $5 \mathrm{~W} 2 \mathrm{H}$, realizou o diagrama de Ishikawa para identificar as causas e os efeitos de um possível problema no desenvolvimento do produto, conforme ilustrado na Figura 9. 
Figura 9.

Diagrama de Ishikawa

\section{Estudo para Engenharia de Produto desenvolver Haste do Fecho}

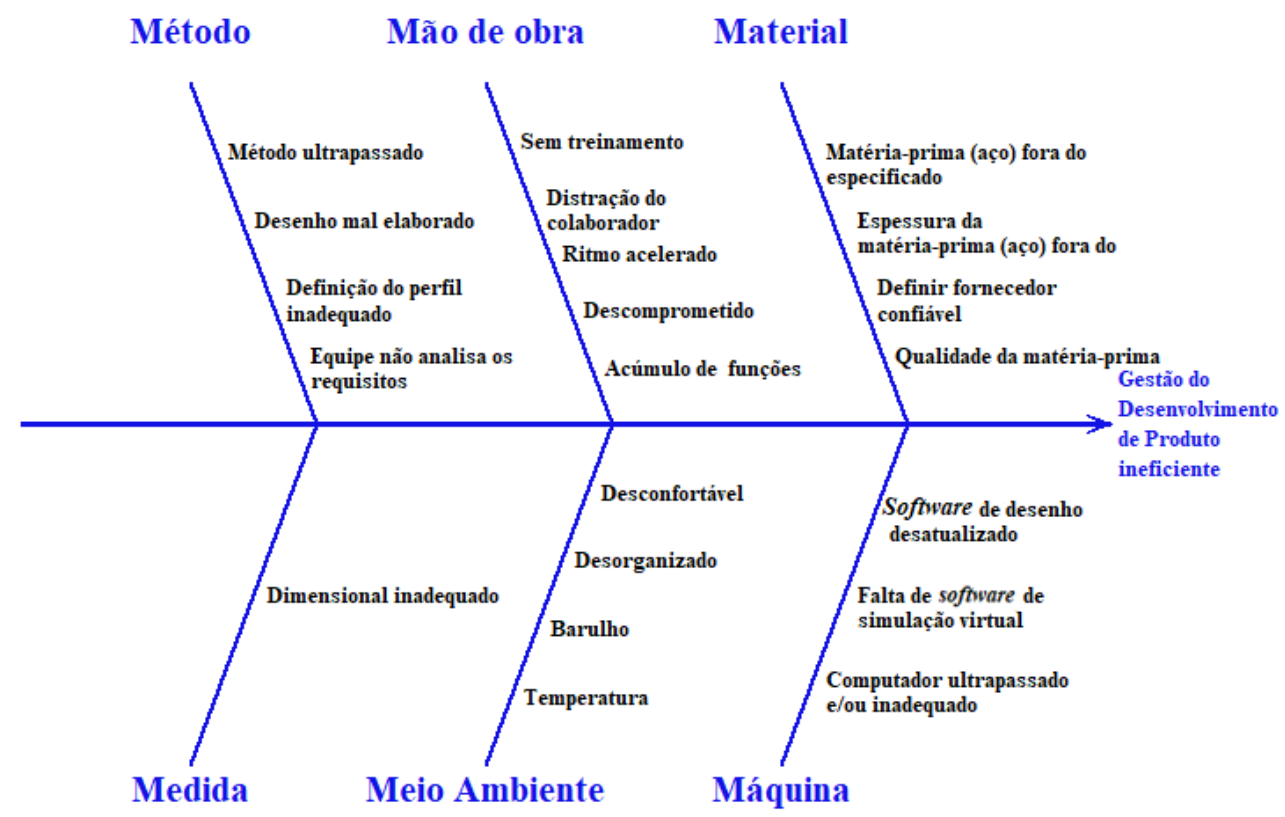

Fonte: Elaborado pelos autores (2021).

Após o diagrama de Ishikawa, a equipe realizou uma matriz de causa e efeito, com o objetivo de equacionar as principais causas do problema. De acordo com Bastos, Santos, Reis e Linhares (2019), essa matriz possibilita identificar essas causas, especificando eventuais motivos e designando-os em ordem do impacto que ocasionam na empresa. Com base nessa equalização de valores, foi realizado um diagrama de Pareto para a melhor intepretação e visualização de causa e efeito. Para tanto, utilizou-se o princípio 80/20. As 21 variáveis descritas no diagrama de Ishikawa foram dispostas num gráfico, conforme ilustrado na Figura 10. 
Figura 10.

Diagrama de Pareto

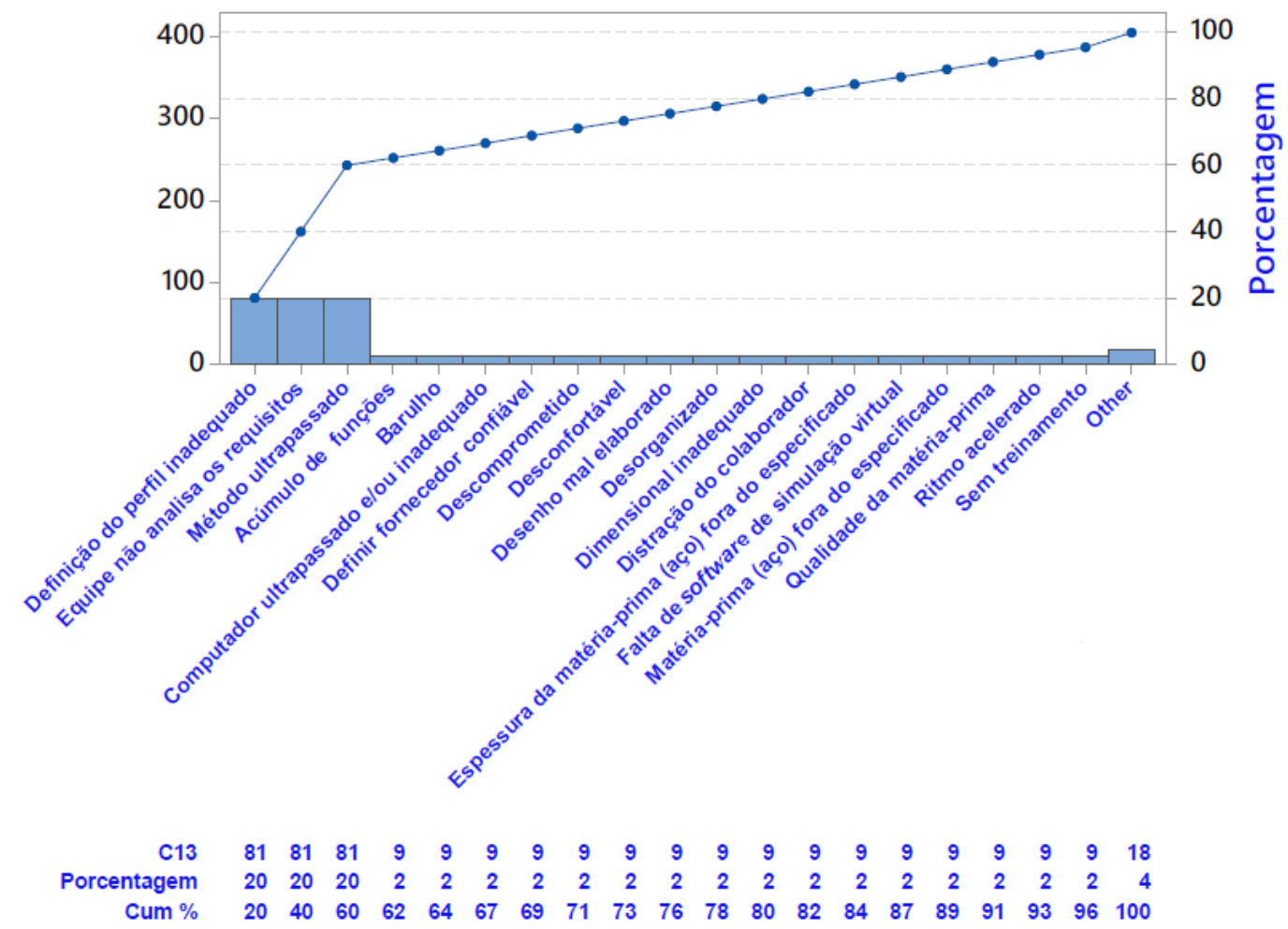

Fonte: Elaborado pelos autores (2021).

\subsubsection{Execução da etapa measure}

As atividades desenvolvidas na etapa define proporcionaram subsídios para a realização da etapa measure. $\mathrm{Na}$ etapa define, toda a equipe conheceu as características desse componente, e posteriormente se iniciaram as atividades da etapa measure. O requisito de força de tração determinou o atendimento de uma força de tração igual ou maior que $22 \mathrm{KN}$. Agora na etapa measure foi dimensionado esse requisito.
$\mathrm{Na}$ etapa measure, além de dimensionar a força necessária a que o componente deve resistir, foi feita uma árvore das características críticas para a qualidade (CTQ), um fluxograma de processo utilizado para apontar as características de qualidade por meio da perspectiva do cliente, auxiliando na identificação dos problemas. A Figura 11 ilustra a árvore CTQ desenvolvida para esse projeto. 
Figura 11.

Árvore das Características Críticas Para a Qualidade (CTQ)

VOZ DO CLIENTE

CRITICO PARA A QUALIDADE

REQUISITO DE DESEMPENHO

Desenvolver Terminal de Ancorage atenda à Norma do Cliente e monte no veículo

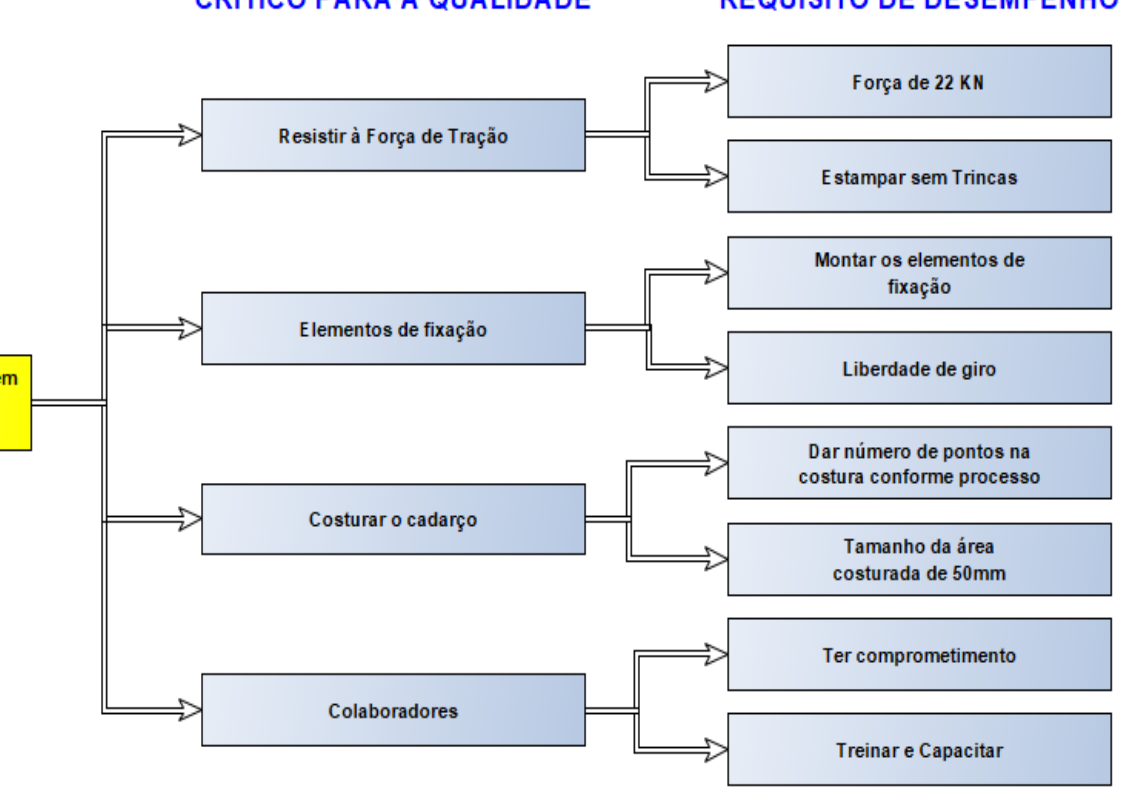

Fonte: Elaborado pelos autores (2021).

\subsubsection{Execução da etapa analyze}

A terceira etapa, analyze, determinou conceitos de projeto. Foram analisadas as atividades realizadas anteriormente e definiu-se um conceito de produto mais adequado para atender ao requisito de força apontado pelo cliente, 22 $\mathrm{KN}$.

Após a escolha de um conceito do terminal de ancoragem, foi realizada uma reunião de análise dos efeitos e modos de falha em projeto. Mediante a participação de uma equipe multidisciplinar, descreveram-se todos os possíveis modos de falha do produto e determinaram-se todas as características críticas para esse desenvolvimento.

\subsubsection{Execução da etapa design}

Na etapa de design, foi desenvolvido um perfil de terminal de ancoragem. Utilizando o software Catia V5, modelou-se uma proposta que atendesse às premissas definidas nas etapas anteriores. Após o modelamento de um perfil ideal, foi realizado um ensaio de tração virtual no software LS-Dyna, de simulação multifísica. O modelo nesse software foi parametrizado e realizado numa simulação de tração, conforme ilustrado na Figura 12. 


\section{Figura 12.}

Ensaio Virtual de Tração Direta

ANTES

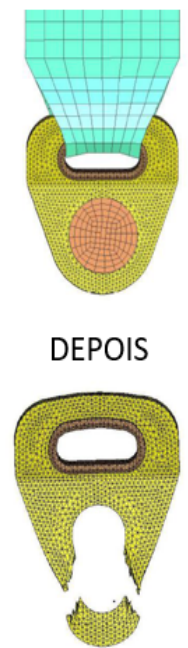

GRÁFICO DE FORÇA

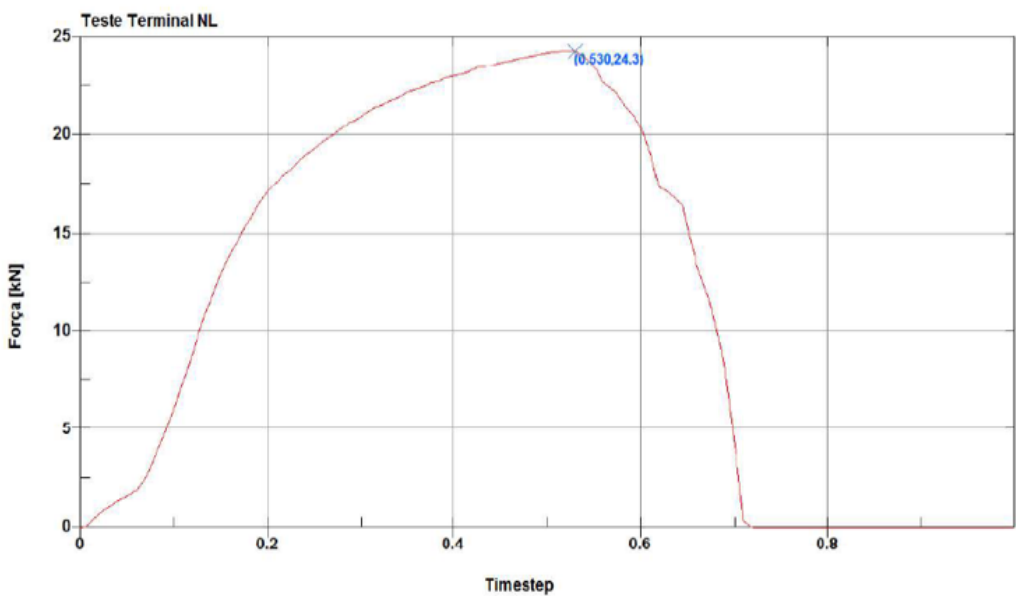

Fonte: Elaborado pelos autores (2021).

De acordo com o resultado da simulação virtual, o terminal de ancoragem rompe na parte inferior com uma força de 24,3 KN. Portanto, o perfil modelado atendeu ao requisito de força com porcentagem superior de $10 \%$.

Com essa aprovação, foi manufaturado o protótipo do terminal de ancoragem, em ferramenta não produtiva. Os componentes foram ensaiados em laboratório, e, com a aprovação, iniciou-se o planejamento da construção do ferramental para a realização de produção em pequena e larga escalas.

\subsubsection{Execução da etapa verify}

$\mathrm{Na}$ etapa verify, o design já foi aprovado, o ferramental construído e iniciou-se a produção em pequena escala. Para a validação desse ferramental, foi realizado o try-out de acordo com o procedimento das outras fases do APQP, contendo todas as documentações realizadas pela engenharia de processo e acompanhamento de toda a equipe.

Após a produção do try-out fizeramse a análise dimensional do produto $\mathrm{e}$ ensaios em laboratório de testes para validação. Após essas aprovações, foram enviadas amostras para o cliente realizar a montagem e os ensaios. Os resultados das cinco peças ensaiadas no teste de tração direta são ilustrados na Tabela 1. Todas as peças obtiveram resultado acima dos $22 \mathrm{kN}$, o mínimo exigido. 
Tabela 1.

Ensaio de Tração

\begin{tabular}{cccc}
\hline $\begin{array}{c}\text { AMOSTRA } \\
\mathrm{N}^{0}\end{array}$ & IDENTIFICAÇÃO & $\begin{array}{c}\text { FORÇA } \\
\text { MÁXIMA KN }\end{array}$ & $\begin{array}{c}\text { FORÇA } \\
\text { MÁXIMA N }\end{array}$ \\
\hline 1 & CR021R305 & 23,95 & 23953,13 \\
2 & CR021R306 & 23,63 & 23634,4 \\
3 & CR021R307 & 23,66 & 23658,92 \\
4 & CR021R308 & 23,86 & 23855,06 \\
5 & CR021R309 & 24,22 & 24224,74 \\
\hline
\end{tabular}

Fonte: Elaborado pelos autores (2021).

Este estudo mostrou que é possível unir duas metodologias consagradas no desenvolvimento de produto. A aplicação do método DMADV da metodologia Design for Lean Six Sigma, auxiliou a gestão da Engenharia de Desenvolvimento de Produto na segunda fase do APQP em uma empresa automotiva.

E por fim, os resultados deste estudo agregou evidências, ao proporcionar o desenvolvimento de um componente do cinto de segurança assertivo, enquanto os antigos desenvolvimentos, foram descritos com decisões errôneas que agregaram recursos financeiros em retrabalhos que não tinham sido considerados para o projeto. Portanto, este trabalho desenvolveu um fluxo de atividades para incorporar na segunda fase do APQP. A Figura 13 ilustra as atividades da segunda fase do APQP atuais e um fluxo com as atividades do DMADV incorporadas a essa fase. 


\section{Figura 13.}

Fluxo da Segunda Fase do Advanced Product Quality Planning

FASE 2 - Projeto e Desenvolvimento de Produto

\begin{tabular}{|c|}
\hline Fluxo Atual \\
\hline 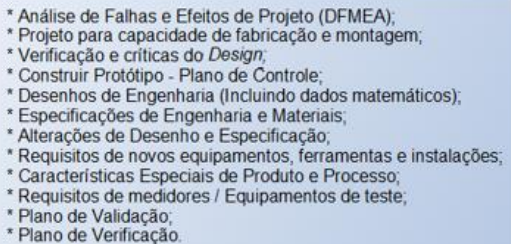 \\
\hline
\end{tabular}

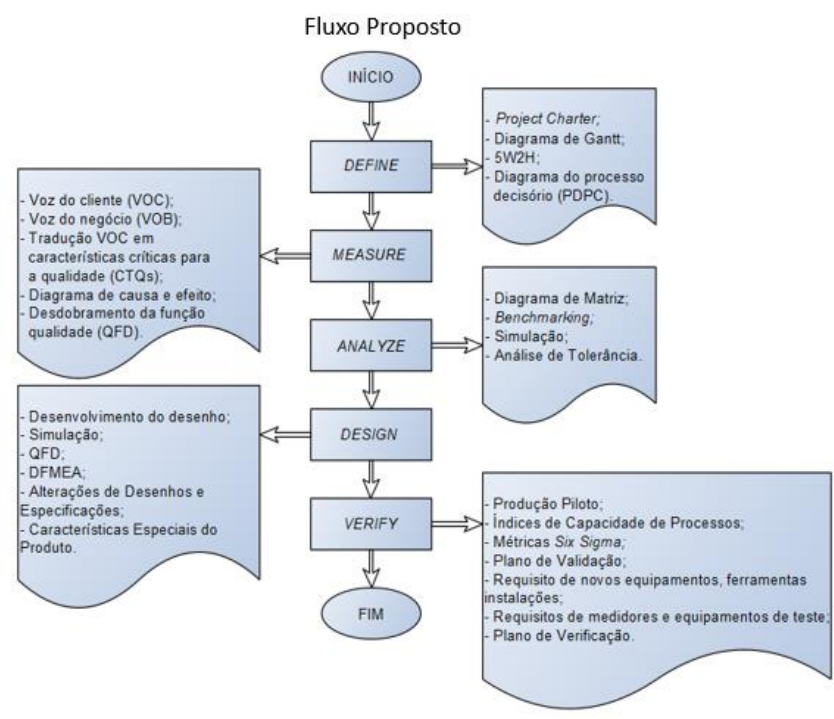

Fonte: Elaborado pelos autores (2021)

\section{Considerações finais}

A presente pesquisa, por meio de um estudo de caso qualitativo, permitiu apresentar duas metodologias utilizadas em gerenciamento de desenvolvimento de produtos. Após a criação do estado da arte nesse assunto, obteve-se conhecimento para desenvolver uma proposta de melhoria na segunda fase do APQP, proporcionando a esse gerenciamento características de um projeto six sigma.

A metodologia Design for Lean Six Sigma, de um modo geral, é apontada como um tema em crescimento no campo acadêmico e no meio profissional. Poucos trabalhos têm combinado o tema gestão de desenvolvimento de produto com as atividades do método DMADV. Porém verificou-se que o tema APQP é um pouco mais divulgado para este gerenciamento.

As atividades descritas no método DMADV, utilizadas neste projeto, mostraram que, se elas forem aplicadas acertadamente, as metas estabelecidas na atividade Project Charter da Etapa define serão alcançadas. Desta maneira, este trabalho tornou capaz a união de duas metodologias consagradas, APQP e Lean Six Sigma, no gerenciamento do DNP, sendo que ambas estão introduzidas no desenvolvimento diário de inúmeras empresas de pequeno, médio e grande porte, ou seja, instrumentos disponíveis, de fácil 
assimilação e aplicação nas atividades de operações.

Como continuidade de pesquisas após o presente artigo, os autores verificaram a oportunidade da execução desse modelo de gerenciamento, em uma ou mais empresas de diferentes áreas, apresentando a utilização de outras atividades e tornando o método mais abrangente. Desta maneira, foram enumerados alguns tópicos a serem considerados:

- Constatar que o prazo definido pelo cliente permitirá que as atividades sejam realizadas;

- Definir cuidadosamente a equipe que irá trabalhar no projeto que deve ser multidisciplinar envolvida no êxito da metodologia;
- Estabelecer que as atividades que sejam realizadas pela Engenharia, estão de acordo com o produto e recursos da empresa;

- Certificar um bom fluxo de informações, no que se trata das respostas alcançadas nas atividades das etapas do DMADV.

Para concluir, ao analisar os resultados alcançados, é possível conceituar que houve contribuição para o aprendizado e entendimento das metodologias utilizadas no gerenciamento de desenvolvimento de produto em uma empresa automotiva. Deseja-se que a disseminação do conhecimento atingido e a execução deste método, proporcione decisões mais assertivas para a Engenharia de desenvolvimento de produto no PDP e desenvolvimento de produtos mais sustentáveis.

\section{Referências}

Advanced Product Quality Planning and Control Plan (APQP). (2008).

Publication manual of APQP. Michigan: Automotive Industry Action Group.

Albertin, M. (2018). Planejamento avançado da qualidade: sistemas de Gestão, técnicas e ferramentas. Rio de Janeiro: Editora Alta Books.

Alonso, A., Lima, M., \& Almeida, R. de. (2016). Métodos de pesquisa em
Ciências Sociais: Bloco

Qualitativo. São Paulo: CEBRAP Sesc São Paulo.

Alves, M. C., \& Azevedo, P. S. (2016). Integração das metodologias do PDP e PMBOK na área de gestão do design. Revista Projetica, 7(2), 25-37. https://dx.doi.org/10.5433/22362207.2016v7n2p25 
Bastos, L. S., Santos, J. P. B., Reis, E. M.

B., \& Linhares, L. (2019).

Aplicação de ferramentas de gestão em propriedades leiteiras: um

estudo de multicaso. Revista

Agrária Acadêmica, 2(5), 158-168. https://doi.org/10.32406/v2n52019/ 158-168/agrariacad

Clark, K. B., \& Fujimoto, T. (1991). Product development performance: strategy, organization and management in the world auto industry. Boston: Harvard Business School Press.

Gerhardt, T. E., \& Silveira, D. T. (2009). Métodos de pesquisa. Porto Alegre, RS: Editora da UFRGS.

Godoy, A. S. (2006). Estudo de caso qualitativo. In C. K. Godoi, R. B. S. Melo, \& A. B Silva (Org.), Pesquisa qualitativa em estudos organizacionais: paradigmas, estratégias e métodos (pp. 115146). São Paulo: Saraiva.

Godoy, A. S. (1995). A pesquisa qualitativa: tipos fundamentais. Revista de Administração de Empresas, 35 (3), 20-29. https://doi.org/10.1590/S003475901995000300004

Lobo, R. N. (2020). Gestão da Qualidade. São Paulo, SP. Editora Érica. Recuperado em 17 out. 2021, de https://books.google.com.br/books? $\mathrm{hl}=\mathrm{pt}-$

BR\&lr=\&id=S8y8DwAAQBAJ\&oi $=$ fnd $\& p g=$ PT $18 \& d q=$ gest $\%$ C $3 \%$ A 3 o+da+qualidade \&ots $=B R n V t c Z 9 u h$ $\& \operatorname{sig}=x J q 7 \mathrm{ckVUI3cJRJ6CVm41G}$ M-

$\mathrm{hF} 5 \mathrm{Y} \# \mathrm{v}=$ onepage $\& \mathrm{q}=$ gest $\% \mathrm{C} 3 \% \mathrm{~A}$ $30 \% 20 \mathrm{da} \% 20$ qualidade $\& \mathrm{f}=$ false
Marconi, M. A., \& Lakatos, E. M. (2017). Fundamentos da metodologia científica. (8a. ed. 2a. reimpressão). São Paulo: Atlas.

Martins, M. M. (2018). Análise da adoção do sistema de gestão da qualidade IATF 16949:2016 no segundo nível da cadeia de fornecimento da indústria automobilística brasileira. Augusto Guzzo Revista Acadêmica, 1(22), 141-160. DOI: 10.22287/ag.v1i22.791

Marion, T. J., Eddleston, K. A., Friar, J. H., \& Deeds, D. (2015). The evolution of interorganizational relationships in emerging ventures. an ethnographic study within the new product development process. Journal of business Venturing, 30(1), 167-184. DOI:10.1016/j.jbusvent.2014.07.00 3

Oliveira, F. R., França, S. L. B, \& Rangel, L. A. D. (2018). Princípios de economia circular para o desenvolvimento de produtos em arranjos produtivos locais. Interações - Revista Internacional de Desenvolvimento Local, 20(4), 1179-1193. https://dx.doi.org/10.20435/inter.v2 0i4.1921

Palisaitiene, J. K., Sundin, E., \& Poksinska, B. (2018). Remanufacturing challenges and possible lean improvements. Journal of Cleaner Production, 172(1), 3225-3236. https://doi.org/10.1016/j.jclepro.20 17.11.023

Pissinatti, T. P., Franco, J. C., \& Rezende, J. P. (2014). Inter-relação da ferramenta APQP e do guia 
PMBOK para eficiência nas etapas de implementação de novos projetos na indústria automotiva. Iberoamerican Journal of Project Management, 5(1), 21-41.

Prodanov, C. C., \& Freitas, E. C. (2013). Metodologia do trabalho científico: métodos e técnicas da pesquisa e do trabalho acadêmico. Rio Grande do Sul: Feevale.

Reis, Z. C., Costa, C. A., Milan, G. S. (2017). Identificação de fatores antecedentes na implementação da filosofia Lean no processo de desenvolvimento de produtos. Exacta - EP, 15(2), 303-321. https://doi.org/10.5585/exactaep.v1 $5 \mathrm{n} 2.6743$

Rocha, J. R. P.; SALERNO, M. S. (2014). $O$ papel do APQP - Advanced Planning for Product Quality no desenvolvimento de produtos: Análise de casos na relação montadora-autopeças. Gestão e Produção, 21(2), 231-243. https://dx.doi.org/10.1590/0104530X1139

Rossetto, V., Toso, B. R. G. O., \& Rodrigues, R. M. (2019).

Fluxograma organizativo de atenção domiciliar às crianças com necessidades especiais de saúde. REBEn, 73(4), 1-8. https://dx.doi.org/10.1590/00347167-2019-0310

Rotondaro, R. G., Balestrassi, P. P., Braz, M. A., Carvalho, M. M., Ho, L. L., Laurindo, F. J. B., Nakano, D., Miyaye, D. I., Ribeiro, C. O., \& Ramos, A. W. (2002). Seis sigma: estratégia gerencial para a melhoria de processos, produtos e serviços. São Paulo: Atlas.
Rozenfeld, H., Forcellini, F. A., Amaral, D. C., Toledo, J. C., Silva, S. L., Alliprandini, D. H., \& Scalice, R. K. (2012). Gestão de desenvolvimento de produtos: uma referência para a melhoria do processo. São Paulo: Saraiva.

Santos, P. V. S.; \& Oliveira, T. C. T. (2019). Case study on the application of quality tools in service level management. ITEGAM- Journal of Engineering and Technology for Industrial Applications (ITEGAM-JETIA), 5(17), 75-81. https://dx.doi.org/10.5935/24470228.20190011

Schineider, O. A., \& Gasparotto, A. M. S. (2020). O papel do APQP (Advance Product Quality Planning) no produto final com foco no cliente. Interface Tecnológica. 17(2), 755766. https://doi.org/10.31510/infa.v17i2. 998

Silva, A. M., \& Moura, E. M. (2018). Metodologia do trabalho científico. (3a ed.). Fortaleza, CE: Ed. UECE.

Toledo, J. C., Alliprandini, D. H., Ferrari, F. M., Martins, M. F., Martins, R. A., \& Silva, S. L. (2002). Modelo de referência para gestão do processo de desenvolvimento de produto: aplicações na indústria brasileira de autopeças. São Carlos: UFSCar/Fapesp.

Werkema, C. (2012). DFLSS - design for lean six sigma: ferramentas básicas usadas nas etapas $D$ e $M$ do $D M A D V$. Rio de Janeiro: Elsevier. 
Werkema, C. (2020). Lean seis sigma:

introdução às ferramentas do lean

manufacturing. São Paulo: Atlas. 